\title{
CIUDAD, ESTALLIDO SOCIAL Y DISPUTA GRÁFICA
}

\author{
CITY, SOCIAL OUTBREAK AND GRAPHIC DISPUTE
}

\section{LUIS CAMPOS MEDINA*, ORIANA BERNASCONI RAMÍREZ ${ }^{* *}$}

Resumen: En este texto reflexionamos sobre las prácticas de inscripción y borramiento generadas a raíz del estallido social de octubre de 2019 en Chile. Partiendo de la idea de que ellas dan luces acerca de las formas de relacionarse de modo corporal y sensible con y en la ciudad, nos interesa mostrar la relevancia que ambas poseen en tanto herramientas de producción del territorio y de disputa por el significado de los lugares. A través del contrapunto entre los rasgos detectados en las prácticas de inscripción gráfica y sus antagónicas prácticas de borramiento buscamos probar la plausibilidad de un abordaje analítico que las entienda formando parte de dispositivos. Para ello entregamos ejemplos concretos generados mediante revisión de prensa de casos emblemáticos ocurridos en la ciudad de Santiago. Lo anterior permite captar su incidencia sobre el modo de vincularnos sensorial y corporalmente con el espacio urbano, así como entender mejor las nuevas territorialidades que genera la protesta.

Palabras Clave: Disputa gráfica, territorio, ciudad, protesta.

АвsтRACT: In this text we reflect on the inscriptions and effacement practices generated as a result of the social outbreak of October 2019 in Chile. Starting from the idea that they shed light on the ways of relating in a bodily and sensitive way with and in the city, we are interested in showing the relevance that both have as tools of production of the territory and of dispute over the meaning of places. Through the counterpoint between the features detected in the graphic inscription practices and their antagonistic effacement practices, we seek to test the plausibility of an analytical approach that understands them as part of devices. This allows us to capture their impact on the way we link at sensory and bodily level with the urban space, as well as better understanding the new territorialities generated by the protest. We provide examples generated through a press review of emblematic cases in the city of Santiago de Chile.

KEYwORDs: Graphic dispute, territory, city, protest.

Recibido: 08.09.2020. Aceptado: 06.10.2021.

\footnotetext{
* Doctor en Sociología (EHESS), Instituto de la Vivienda de la Universidad de Chile, Santiago, Chile. Correo electrónico: luiscampos@uchilefau.cl. Orcid: http://orcid.org/0000-0002-5157-4974

** Doctora en Sociología (London School of Economics), Universidad Alberto Hurtado, Santiago, Chile. Correo electrónico: obernasc@uahurtado.cl. Orcid: https://orcid.org/0000-0002-0685-124X
} 


\section{INTRODUCCIÓN}

$\mathrm{O}$ CTUBRE DE 2019 es el mes de inicio del llamado "estallido social" chileno. Como producto del alza en la tarifa del pasaje del metro de la ciudad de Santiago, se desencadenó una serie de protestas y manifestaciones que llevaron a que el día viernes 18 la ciudad de Santiago quedara casi sin transporte público, ya que muchos jóvenes se tomaron las estaciones del metro, impidiendo la circulación del ferrocarril subterráneo. A los pocos días, la autoridad de gobierno decretó el toque de queda. Desde entonces, las manifestaciones, marchas y concentraciones de protesta no dejaron de sucederse día tras día. Solo la emergencia sanitaria generada por el COVID-19, en el mes de marzo de 2020, consiguió detener las expresiones de descontento de la población de la ciudad y del país.

El estallido social de octubre también ha sido un estallido gráfico. Así lo atestiguan diversas iniciativas, entre las que destacan los sitios web "La ciudad como texto" (www.laciudadcomotexto.cl), el "Museo del Estallido Social" (https://www.instagram.com/museodelestallidosocial/), y publicaciones tales como "De Manifiesto" (Cisternas et al., 2020), "Alienígenas" (Quiroga y Pastén, 2020, "Hablan los muros" (Molina, 2020), "Fragmentos de un Despertar" (Slachevsky, 2020) o "Valdivia presente" (Juica, 2020). En efecto, una de las vías de expresión más importantes de la disconformidad social ha sido el escrito en los muros, los rayados y la elaboración de afiches y pancartas. Previo a ese viernes de octubre aparecieron, en diversos puntos de la ciudad, escritos que llamaban a la evasión del pasaje del metro. A continuación, como una suerte de explicación y una forma de enrostrar las razones del estallido social a una élite atónita, proliferó un escrito que se volvió popular: "No son 30 pesos. Son 30 años", dando a entender que las causas de la agitación social no se limitaban a un asunto tarifario, sino que trascendían con mucho las dificultades de movilización de los habitantes de la urbe. Le siguieron otros textos como "No + abusos", "Chile despertó" e incontables "ACAB" o "1312".

Santiago y otras ciudades del país se fueron inundando progresivamente de escritos en calles y muros a través de los cuales se dio forma pública a las motivaciones y justificaciones de la movilización, de la contestación y del desacato (Denis y Pointille, 2009, p. 94; Latour y Weibel 2005, p. 14), y esto a pesar de la insistencia de las autoridades de gobierno en que el movimiento no tenía un petitorio claro.

Frente a esas inscripciones gráficas de protesta, aparecieron prácticas de borramiento, vale decir, acciones dirigidas a "restaurar la normalidad", al 
modo expuesto por Suazo (2019), a hacer desaparecer las escrituras y rayados elaborados por manifestantes y reemplazarlas por una capa de pintura que las volviera invisibles para el transeúnte, ilegibles por parte del ciudadano, inocuas en su potencial político. Las autoridades de gobierno -nacional y municipal- no siempre reconocieron estar detrás de estas acciones, pero la sensación generalizada fue que ellas eran las autoras intelectuales de los borramientos. De hecho, estas prácticas de borramiento se convirtieron en una constante, como atestigua una comparación del estado actual (agosto 2020) de la vereda sur de la Alameda con el registro antes citado de "La ciudad como texto", realizado el 23 de noviembre de 2019.

En este artículo reflexionamos sobre las prácticas de inscripción y borramiento generadas a raíz del estallido social de octubre en Chile, bajo el entendido de que ellas son relevantes para entender los procesos de transformación del significado y simbolismo de los lugares, pero también porque dan luces acerca de las formas de relacionarse de modo práctico, corporal y sensible con y en la ciudad.

\section{INSCRIPCIONES GRÁFICAS Y TERRITORIO}

Según Lefebvre (1974) cualquier sociedad genera su espacio de manera progresiva, a través de una interacción dialéctica entre la organización social y el espacio. Solo que, más que de una práctica singular, cabe plantear que se trata de una multiplicidad de ellas, las que a veces se articulan y potencian, mientras que en otras ocasiones se contrarrestan y dispersan. Esas prácticas espaciales poseen, además, su ritmo y dinámica propia: en ocasiones se ralentizan; en momentos de agitación social y protesta algunas de ellas se aceleran e intensifican (Campos, 2019).

La inscripción gráfica es una de esas prácticas espaciales. A través de la producción de grafitis, tags y murales -entre otras-, individuos y colectivos graban materialmente su presencia, su existencia social, pero también sus demandas, intereses y visiones de la realidad, sus formas de relacionarse con la memoria y la historia, con el presente y el futuro.

En el caso chileno, el estudio de las formas de intervención gráfica ha privilegiado los análisis de tipo histórico y estético, enfocándose en las tradiciones pictóricas, como en el caso de la obra de Castillo (2006); las ideologías que soportan su producción, en el caso de la obra de Vico y Osses (2009); o la adscripción política y la función de protesta, como proponen en su trabajo Cristi y Manzi (2016) y Sandoval (2001), por mencionar solo 
algunos trabajos. Más incipiente es la perspectiva que las aborda como formas de intervención y marcas de apropiación del espacio urbano, como en los actuales trabajos de Aguirre (2020), Bauerle (2019) y Oliva (2020). En esa dirección, complementando la perspectiva que las considera como un vehículo o medio de comunicación -como en las propuestas de Dittus (2019) y Manzi (2020) - conviene entenderlas en su capacidad de producir territorio.

Si seguimos a Deleuze y Guattari (1980), el territorio se constituye por y a través del surgimiento de formas de expresión: "es la emergencia de materias de expresión (cualidades) la que va a definir el territorio" (p. 387, trad. propia) y responde necesariamente a una actividad de marcaje, a la producción de índices sensibles: el territorio está "esencialmente marcado por "índices", y estos índices "se toman de componentes de todo tipo de orígenes" (Deleuze y Guattari, 1980, pp. 386-387, trad. propia).

El territorio se comporta como un haz de cualidades sensibles que tienen la capacidad de modelar el medio habitado, pero también a los ocupantes de ese medio, tal como subraya en su trabajo Aubán (2017). El carácter y variedad de los elementos que inciden en la producción de territorio destacan su complejidad. El dinamismo de esos elementos subraya la condición histórica del territorio. Pero lo anterior no debe hacer perder de vista que el territorio es el producto de "miles y miles de sistemas de relaciones que van tejiendo una red de frágiles equilibrios susceptibles de ser disueltos en cualquier momento" (Aubán, 2017, p. 79). Las inscripciones gráficas son uno de esos elementos, ellas hacen cosas, en la medida en que pueden ser entendidas como "actos de habla" (Austin, 2003; Searle, 2001) y por eso conviene aproximarse a su estudio desde una perspectiva pragmática.

Abordar dicho enfoque pragmático implica complementar el análisis de la significación y la interpretación de los textos, subrayando que toda inscripción juega un rol en los entornos socio-materiales y contribuye a definir la ecología de las situaciones (Denis y Pointille, 2009, pp. 94-101; 2013, pp. 17-30). Implica entender que esas inscripciones vuelven visibles las delimitaciones organizativas y sensibles de nuestro mundo, como han señalado Riffaud y Recours (2016), y desencadenan efectos prácticos que van más allá del contenido semántico de sus textos.

Desde este enfoque se trata de prestar atención a las características y condiciones de la agencia de las inscripciones gráficas, la que sin duda alude a la composición textual de los escritos, particularmente a aquello que buscan hacer las palabras y frases, como lo han señalado Austin (2003) y 
Searle (2001). Pero se trata también -y de manera fundamental- de prestar atención a su emplazamiento y materialidad, a los modos de aparición del escrito, su temporalidad y permanencia, su capacidad de integrarse o intervenir los paisajes de quienes las observan. En resumen, prestar atención a su condición de "actos de escritura" (Fraenkel, 2007).

Los rasgos recién indicados dotan a los escritos de la capacidad para incidir en las acciones y los comportamientos de sus observadores, en la percepción sensorial y las emociones que desencadenan, lo que se ha denominado la "fuerza estésica" de los escritos (Fraenkel, 2008, p. 163), lo que a su vez repercute en que las inscripciones gráficas conviertan el espacio público en un "espacio de influencia" (Fraenkel, 2017, p. 319).

Además de generar este efecto pragmático, el surgimiento, modalidad de aparición, presencia y persistencia de las inscripciones gráficas constituye un potente indicador de las modalidades de producción, apropiación y control del espacio urbano. Como postula Artières (2013), el escrito en la ciudad es un objeto de vigilancia acérrima y desde la modernidad será considerado un "cuerpo vivo" que "actúa, se transforma, se reproduce, reúne, circula, prolifera, se difunde..." (p. 15, trad. propia).

Esta dimensión activa y política del escrito es recuperada, en el caso chileno, por Araya (2007), quien, a través del análisis de una serie de intervenciones, muestra cómo el escrito "quiere subvertir el soporte mismo sujeto a control" y nos muestra que "el espacio público está en juego, en disputa, siempre, inefablemente sujeto a las formas" (p. 444).

Araya alude a inscripciones y contra-inscripciones, lo que nos recuerda que junto al escrito suele aparecer el borrado. Consideramos pertinente el recurso al neologismo "borramiento" para reforzar la condición activa y procesual de dicha práctica, oponiéndose a una consideración meramente reactiva e ingenua que la clasifica inmediatamente como una forma de restitución. Por el contrario, basados en el enfoque pragmático es importante resaltar la condición performativa del acto de borrar, entendiendo que él también constituye una inscripción, una intervención sensible que actúa sobre el espacio urbano y sobre las modalidades de territorialización. Las prácticas de borramiento se oponen a las escrituras en el espacio público, y que, en su supuesto empeño por restaurar, generan algo nuevo, tensionando la sensibilidad, las posibilidades de significación y de apropiación. Dicho de forma sintética, las prácticas de borramiento instalan y materializan la disputa. 


\section{ESTALLIDO SOCIAL Y DISPUTA GRÁFICA}

En el estallido social de octubre de 2019, el incremento en la producción de escritos, así como la diversidad de lugares y superficies en las que aparecieron fue inusitada. Fueron rayados muros, fachadas de viviendas, edificios públicos, estaciones de metro, mobiliario urbano, monumentos, incluso el suelo. Aparecieron rayados, pero también tags, afiches, papelógrafos, stencils, autoadhesivos. La magnitud de la intervención producida da cuenta de una transformación en la "atmósfera gráfica" (Fraenkel, 2002, p. 46) de la ciudad, puesto que gran parte de ella fue rayada y en un sentido muy distinto del que usualmente tienen las intervenciones gráficas urbanas convencionales.

En efecto, entre los escritos urbanos predominan las señaléticas y la publicidad. Sin embargo, a veces, surgen también escritos de expresión ciudadana cuya función principal puede ser descrita como el dar expresión a necesidades y exigencias que, de lo contrario, se mantendrían difusas y efímeras, solo a nivel de lo oral y lo conversacional. La escritura supera la inmediatez, separa temporalmente la emisión de la recepción y amplifica las posibilidades de lectura a una diversidad de agentes. Los escritos del estallido social materializan una demanda y le otorgan permanencia y durabilidad: le dan forma en el espacio público o, como se dice actualmente en los estudios sobre activismo y memoria, las performan (Denis y Pointille, 2013; Schindel, 2009).

Los escritos urbanos se caracterizan también por una clara reglamentación de sus modalidades de aparición y mantenimiento: se regula y conserva la señalética, se diseña y mantiene paneles publicitarios, en ambos casos a través del actuar de agentes especializados en esas tareas (Latour y Hermant,1998; Denis y Pontille, 2010). Esa reglamentación incluso abarca la autorización de manifestaciones y protestas en las que se suele utilizar escritos políticos.

Todo esto fue subvertido durante el estallido social: se utilizó paneles de señalética como soportes para escritos contestatarios; se borró escritos comerciales y se los reemplazó por escritos políticos. Se rayó fachadas de edificios, estatuas e iglesias. No se pidió autorización y cualquier tipo de objeto o superficie se convirtió en soporte para la intervención gráfica.

Distintos autores han mostrado cómo la aparición y proliferación de escritos constituyó una intervención sobre la estabilidad y la regularidad del ordenamiento urbano, el simbolismo de los lugares y la legitimidad de los monumentos, como es el caso de los textos de Aguirre (2020), Bauerle 
(2019), Dittus (2019), Manzi (2020) y Oliva (2020). Pero hay un aspecto que no ha sido tematizado: dada la magnitud de la intervención, se produce un efecto agregado, esto es, que el sentido y la relevancia de las intervenciones gráficas deja de ser únicamente singular - para cada intervención de forma aislada- y pasa a resonar con el conjunto de ellas. Proliferan los escritos, los tipos de escritos, las temáticas, los emplazamientos y, por cierto, los autores y potenciales autores de los escritos. Estos escritos se relacionan entre sí, se citan, refieren y reenvían (Taylor, 2003, p. 34). La ciudad deviene espacio de iterabilidad y citacionalidad extendidas (Bernasconi \& Ruiz, 2018, pp. 228-249).

Los escritos del estallido expresaron el conjunto de demandas ciudadanas, la variedad de peticiones hechas por los habitantes a sus autoridades. Ellos plasmaron el proceso de definición progresiva de las exigencias, mostraron lo común de las necesidades, contribuyeron al perfilamiento de los actores del conflicto y la formulación de los antagonismos. Registraron la violencia en sus variadas formas y atestiguaron sobre los riesgos y peligros de la protesta, pero todo ello lo hicieron materialmente: hubo escritos del tipo mural, hubo recambio permanente de textos, hubo superposición de capas y collage, hubo mensajes distintos conviviendo en un mismo muro y dialogando entre ellos, en una variedad de técnicas y soportes. Todo ello da cuenta de la polifonía de los escritos, pero también es registro material de la protesta y lleva a pensar en el espacio urbano como una suerte de archivo del presente.

\section{DE LA INSCRIPCIÓN}

Para esta reflexión nos interesa detenernos en cuatro rasgos de las inscripciones gráficas del estallido social de octubre que, luego, relacionaremos con características simétricas de las prácticas de borramiento para, así, esbozar los contornos y la densidad de la disputa gráfica involucrada.

El campo gráfico de las disputas políticas: las inscripciones gráficas surgieron en muy diversos espacios, la mayoría no dispuestos para ello, lo que indica que no se encuentran reguladas por la autoridad, sino que tienen su origen en el actuar auto-gestionado de sus autores. Este aspecto es importante, ya que usualmente las reglamentaciones urbanas buscan impedir que los muros y el mobiliario urbano sean intervenidos gráficamente. De hecho, una de las principales preocupaciones para los encargados de aplicar tales reglamentos es que las intervenciones gráficas se propaguen por un 
efecto de imitación (Denis y Pontille 2010). La proliferación, abundancia y persistencia de inscripciones gráficas del estallido social en la ciudad de Santiago hacen ver: a) que cualquier objeto o superficie puede convertirse en un recurso para comunicar $\mathrm{y}$; b) que cualquier objeto puede ingresar al campo de las disputas políticas (Campos, 2019). En el proyecto de "La ciudad como texto" se plantea:

este pliego contiguo de murallas no da abasto, ampliándose orgánicamente hacia paraderos, veredas, rejas, asientos e incluso el mismo suelo, el cual hoy forma parte de este único material gráfico que refleja el imaginario local del período histórico que Chile está experimentando. (www.laciudadcomotexto.cl)

De manera convergente, el trabajo de registro desarrollado por Quiroga y Pastén (2020) resulta indicativo de la magnitud y de las características de la explosión gráfica recién indicada: en un polígono compuesto por nueve manzanas del centro de la ciudad de Santiago (en los bordes del Cerro Santa Lucía) tomaron más de 1.500 fotografías, inventariando 4.068 palabras escritas en diversos tipos de soporte, las que componían un total de 1.131 frases únicas (p. 24).

Afectación dinámica: el dinamismo en la producción y recambio de inscripciones gráficas en los meses del estallido social hizo ver que ellas no aspiraban a la eternidad, sino que buscaban una duración marcada por el aquí y el ahora, por su utilidad para incidir en el presente. Todos los proyectos antes mencionados parten de la premisa de ese dinamismo y evanescencia de la inscripción. Solo a modo de ejemplos se puede mencionar "La ciudad como texto" y De Manifiesto. Mientras que en el primero se declara actuar para "resguardar la memoria grabada en los muros de la calle" y evitar la desaparición de las inscripciones, en el segundo se trata de "evocar lo ausente, y preservar lo efímero del mundo" (Cisternas et al., 2020, p. 8).

El efecto de ello es que se sugiere que el espacio no se encuentra paralizado ni predefinido, sino que es el resultado de un conjunto de operaciones que le dan forma cotidianamente, y que hay una versión alternativa a la pretendida por la autoridad que se caracteriza por la producción ordenada y rutinizada de la atmósfera gráfica de la ciudad. La producción de inscripciones gráficas durante el estallido respondía a las urgencias y necesidades prácticas de sus autores/as, a una temporalidad marcada por la acción y la producción de efectos entre sus lectores/as. Todo ello ha sido reconocido en los proyectos antes citados cuando se recurre a la noción de archivo para 
dar cuenta de la práctica de registro y resguardo de las inscripciones, la casi imperiosa "necesidad de registro", a decir de Quiroga y Pastén (2020, p. 21).

Polifonía y acción plural: Como indicamos anteriormente, la multiplicidad y variedad de temas, grafías y autores fueron atestiguados materialmente por los escritos del estallido. El efecto pragmático de esta pluralidad es sugerir una producción urbana polifónica (Mondada, 2000), que cuestiona el reparto de atribuciones y la jerarquía de tareas convencionalmente establecidas por la autoridad. Con esto, los escritos atestiguan materialmente que es posible actuar de otra manera en nuestras formas de conducirnos en la ciudad y que los potenciales autores de esa posibilidad no son solo las autoridades ni los encargados del mantenimiento cotidiano e invisible de los espacios, como indican Latour y Hermant en su pormenorizado análisis etnográfico (1998), sino que también la ciudadanía, los grupos de personas, los individuos. Es a esa pluralidad en y de la inscripción a la que alude Molina (2020) cuando indica que las "más de quinientas frases recopiladas y transcritas en este libro son una importante colección de la innumerable expresión de la gente. En su transcripción se ha respetado la redacción y la escritura; en algunos casos el uso de letras mayúsculas y/o minúsculas". (p. 19)

El libro da cuenta de una gran variedad de afiches, grafitis, lienzos, carteles y otros soportes en los que se ha plasmado una inscripción.

De manera convergente, el reconocimiento de otras modalidades de actuación e intervención sobre el espacio público es el punto de partida del proyecto que se plasma en el antes citado libro De Manifiesto:

Desde el 18 de octubre, el espacio público ha logrado nuevamente protagonismo, a partir de una ciudadanía que toma consciencia del potencial simbólico que tienen las acciones en el espacio urbano, contribuyendo a un entendimiento de las performances como una nueva forma de activismo ciudadano y de comprender la política. (Cisternas et al., 2020, p. 8)

El espacio en disputa: la proliferación, abundancia y persistencia de inscripciones gráficas en espacios no previstos para ello y muchas veces con un claro sentido de ruptura y contestación sugiere que el espacio público urbano es disputado, es decir, que hay una variedad de concepciones de lo permitido, de lo legítimo y de lo posible, y que esas versiones se contraponen. Con esto, los escritos restauran el carácter cívico y político de la vida 
en ciudad, muchas veces adormecido por una atmósfera gráfica invadida de publicidad y señaléticas que fomenta lectores/as que calculan, planifican y consumen, pero no necesariamente disputan ni contestan.

Parte del sustento de lo anterior se encuentra en lo que hemos afirmado en otro lugar a propósito de la capacidad persuasiva del escrito: esta se encuentra, antes que en el contenido proposicional de la inscripción, en el gesto mismo del rayado: "el escrito en el espacio público persuade, antes que de su contenido mismo, de la posibilidad y validez de intervenir ese espacio" (Campos, 2020, p. 37). Por lo tanto, el incremento de las intervenciones gráficas en el espacio público implica un aumento en las incitaciones a apropiarse de él de forma gráfica: una suerte de invitación a que otros desplieguen este comportamiento insurrecto.

De esta forma, las inscripciones gráficas del estallido van contra la ideología ciudadanista del espacio público (Delgado, 2015), que se asienta en una visión moralizante de los sujetos que componen la comunidad política y que, al mismo tiempo promueve un uso armónico del espacio público buscando desterrar los usos inadecuados (Giglia, 2017), como el rayado.

\section{DEL BORRAMIENTO}

De manera simétrica a estos cuatro rasgos, es posible plantear que las prácticas de borramiento desplegadas en el marco de esta disputa gráfica tienen propósitos opuestos. De acuerdo a Molina (2020) el gobierno actuó de acuerdo a una suerte de pulsión por eliminar rayados, pinturas y grafitis, buscando efectuar una limpieza como si nada hubiese ocurrido, una limpieza que permitiera volver a una supuesta normalidad perdida.

El sábado 26 de octubre, a casi una semana de iniciado el estallido, el gobierno realizó una campaña para eliminar todo tipo de mensajes en las calles y estaciones de metro, en un eficiente plan de borronamiento de las consignas y exigencias que la ciudadanía plasmó en afiches y rayados en diferentes puntos de las ciudades. ¿Por qué era relevante limpiar? Porque estos rayados posibilitan una conciencia permanente de la autorreflexión ciudadana que se había posicionado con el estallido. (Cisternas et al., 2020, p. 9)

En primer lugar, las prácticas de borramiento buscan desactivar la propagación de escrituras, quitando espacios de acción a los escribientes, sustrayendo muros, monumentos y mobiliario urbano a la dinámica comuni- 
cacional que buscaron desencadenar los escritos de protesta. Así, se pretende sugerir que no todo objeto es rayable y que tampoco se le puede incluir a voluntad en las disputas políticas. Se regula el campo gráfico de las disputas políticas, puesto que, como señala Fraenkel (2018), todo régimen político

se esfuerza por controlar estos dos espacios, el espacio público mediático y el espacio público urbano. Pero la brecha entre los poderosos medios de difusión del aparato de propaganda estatal y las pobres técnicas de los manifestantes es en sí misma un mensaje: un simple rayado nos recuerda que el lenguaje es un arma y, mejor aún, que cuando los espacios públicos están cerrados, encadenados, el trazo de un pequeño signo puede contribuir a alimentar la luz de la libertad. (p. 44, trad. propia)

Probablemente, el mejor ejemplo a este respecto lo entregue la actuación respecto de la estatua erigida al general Manuel Baquedano. El periódico en línea Emol aludía a "los trabajos de limpieza y recuperación" de la estatua el 19 de marzo de 2020, coincidiendo con el decreto de estado de catástrofe ${ }^{1}$. Similar cosa se señalaba en la Radio de la Universidad de Chile: "El lugar fue limpiado y pintado completamente durante las primeras horas del estado de catástrofe" ${ }^{\text {. }}$ En diversos medios de comunicación se hablaba de "limpieza", para nombrar a esta primera acción de borramiento. A las pocas horas la estatua volvía a ser rayada iniciándose, con ello, un constante proceso de inscripción y borramiento que llegaría hasta la instalación de un muro en el perímetro de la estatua el 15 de marzo de 2021 con el propósito de impedir la actuación gráfica sobre la estatua, la que, finalmente, fue retirada para realizar trabajos de restauración, dejando el plinto vacío ${ }^{3}$.

En segundo lugar, las prácticas de borramiento pretenden interrumpir la dinámica de producción y recambio de las inscripciones gráficas. Esto se produce mediante la reinstauración de un significado estable y la transmisión de una sensación de regularidad y homogeneidad a los lectores. La comunicación vuelve a generarse a partir de soportes convencionales, a través de tipo de mensajes estandarizados y por tiempos predefinidos, todo lo cual contribuye a reinstaurar el orden. Se desactiva la vivencia cotidiana del espacio urbano "como un vasto campo de fuerzas gráficas en competencia, inestables e imprevisibles" (Fraenkel 2009, p. 160) y se la sustituye por un

\footnotetext{
${ }^{1}$ https://www.emol.com/noticias/Nacional/2020/03/19/980327/plaza-italia-estatua-limpieza.html

${ }^{2}$ https://radio.uchile.cl/2020/03/19/municipalidad-de-providencia-niega-haber-ordenado-limpieza-en-plaza-baquedano/

${ }^{3}$ https://www.uchile.cl/noticias/173755/el-muro-del-plinto-vacio
} 
ordenamiento predecible, por una cadencia anticipable. Se interrumpe la afectación dinámica.

En tercer lugar, las prácticas de borramiento aspiran a reinstaurar la distribución de roles y las formas de participación establecidas por la autoridad para participar de la producción del espacio urbano y así recomponer un espacio regulado y controlado por la autoridad. Se interviene sobre el carácter eminentemente poligráfico de las inscripciones del estallido social desactivando la idea de que cualquier lector se pueda convertir en un potencial autor de escritos, lo que equivale a decir que cortocircuita la capacidad de los escritos para generar disposiciones para la acción en todos sus receptores (Campos, 2020). Se interviene la acción plural y se desactivan la poligrafía y la polifonía.

La ilustración más elocuente sobre lo recién indicado se encuentra en la intervención sobre los muros del centro cultural Gabriela Mistral (GAM), realizada durante la madrugada del 17 de febrero de 2020, sin autorización de la autoridad responsable del mismo, y que dejó la fachada del edificio y casi la totalidad de los escritos y rayados que allí se encontraban, cubiertos por una capa de pintura gris ${ }^{4}$. Esta intervención no fue anunciada por las autoridades de gobierno y en los días posteriores al hecho la prensa no conocía autor ni responsable.

Desde el estallido del 18 de octubre de 2019, la fachada del GAM se había convertido en un importante soporte para las inscripciones de descontento, para muchos casi en el epicentro del grafismo, con intervenciones de importantes artistas callejeros (el ejemplo más elocuente es probablemente el de Caiozzama) y un dinamismo escritural sobresaliente. Tanto así que un medio de comunicación reportaba la realización de un estudio acerca de los rayados por parte de académicos de una importante universidad nacional ${ }^{5}$.

El revuelo causado por esta acción de borramiento fue importante, lo que la llevó a ser abordad en abundantes medios de prensa. Sin embargo, la duración de la pintura gris, al igual que en el caso de la estatua al general Baquedano, fue breve: mucha gente se congregó en las afueras del edificio y comenzó rápidamente a intervenir nuevamente su fachada ${ }^{6}$. A juicio de Molina (2020), la intencionalidad de esta acción fue evidente:

\footnotetext{
${ }^{4}$ https://www.latercera.com/nacional/noticia/quien-pinto-las-paredes-del-gam-borro-los-grafitisla-zona-cero/1015415/

5 https://www.elmostrador.cl/cultura/2020/02/19/callar-la-calle-centro-gam-y-arte-alameda-condenan-el-borrado-de-sus-fachadas-que-registraban-la-historia-del-estallido-social/

${ }^{6} \mathrm{https} / /$ www.elciudadano.com/chile/la-fachada-del-alameda-se-lleno-nuevamente-de-arte-callejero/02/20/
} 
tachar la memoria, los escritos y la gráfica de uno de los lugares icónicos del arte público que ha acompañado la protesta social de estos últimos meses. Con estas acciones se propicia la censura de las expresiones ciudadanas, se promueve la restricción a la libertad de expresión y creación, y se actúa de modo impulsivo para hacer desaparecer las huellas e improntas de acontecimientos en curso, cuya expresión grafiti-artística posee un contenido histórico, estético y social. (pp. 17-18)

En cuarto lugar, las prácticas de borramiento tienen como objetivo mostrar que el espacio público urbano es un espacio consensual para el encuentro armónico de los ciudadanos, definido así por la planificación urbana y resguardado por las fuerzas del orden. Los significados y simbolismos son administrados por la autoridad que interviene sobre la transformación de la ciudad efectuada por los actores de la protesta. Se consensualiza el espacio. Al decir de Giglia (2017), se busca imponer reglas de uso del espacio, lo que implica que se pretende prever y definir los usos adecuados y pertinentes, expulsando la posibilidad de actuaciones no previstas y usos no reglamentados. Se instala la norma de uso correcto, adecuado, moral.

La intervención más ejemplar, a este respecto, es sin lugar a dudas la denominada "paz blanca", efectuada la madrugada del 15 de noviembre de 2019, luego del acuerdo alcanzado por las cúpulas partidarias de redactar una nueva constitución política para la república, y consistente en el despliegue de telas blancas sobre la superficie de la denominada Plaza de la Dignidad y un lienzo, también blanco, colgando de la estatua del general Baquedano con la palabra "paz" . Esta intervención se replicó, en días posteriores, en otras ciudades del país.

\section{CIERRE: DISPOSITIVOS DE BORRAMIENTO Y HORIZONTES POSIBLES}

Los cuatro propósitos esbozados para las prácticas de borramiento sugieren que ellas poseen una condición activa y procesual, y no responden a un actuar reactivo e ingenuo. Además, a través del recurso al orden y la estabilidad, fusionan rayados e inscripciones con otras problemáticas, tales como

\footnotetext{
https://www.emol.com/noticias/Nacional/2019/11/15/967302/Plaza-Italia-acuerdo-Paz-lienzo. html

8 https://www.cooperativa.cl/noticias/pais/manifestaciones/lienzos-por-la-paz-llegaron-a-plazasde-varias-ciudades-en-regiones-de/2019-11-21/164515.html
} 
el deterioro del mobiliario urbano, la suciedad y la contaminación, incluso la delincuencia y el daño del entorno. Esa fusión es bien articulada, y en el caso chileno tiene antecedentes que se remontan por lo menos a la dictadura (Errázuriz, 2009), lo que lleva a pensar que forma parte de un repertorio de acción relativamente estable (Morrison, 2020). Además, esos cuatro propósitos resaltan la condición performativa del acto de borrar y sugieren que las prácticas de borramiento no suceden de modo aislado ni contingente, sino que se ligan a otras prácticas, particularmente las de inscripción, pero también otras, menos visibles, que habilitan su surgimiento, tales como órdenes, autorizaciones, financiamiento, coordinación in situ, entre otras. Consideramos que esto vuelve plausible entenderlas como componentes de conjuntos complejos de prácticas y actividades, verdaderos "dispositivos de borramiento".

Así vistas, las intervenciones que buscan borrar escritos urbanos en el espacio público constituyen, al mismo tiempo, acciones de re-inscripción territorial y actuaciones sobre el registro sensible, que son coordinadas, reiteradas y mantenidas, y se articulan con acciones a nivel legal, como la elaboración de leyes y normativas sobre inscripciones en el espacio público urbano, con el actuar de los medios de comunicación y con la práctica arquitectónica y urbanística9. Solo a modo de ejemplos cabe pensar en la llamada "ley del sticker", que busca sancionar con importantes multas en dinero a las personas que realicen rayados en el transporte público, y que fue rápidamente tramitada por la Cámara de Diputados; o en la cobertura noticiosa a lo ocurrido en la Plaza Baquedano el viernes 15 de noviembre de 2019, cuando fue cubierta con lienzos blancos y la palabra "paz", justo después del acuerdo político entre congresistas de diversos sectores denominado "acuerdo por la paz"; o, finalmente, con las propuestas para "repensar" el espacio del Plaza Italia hechas por arquitectos y oficinas de arquitectura. Para Foucault, un dispositivo refiere a un

aparato estratégico, aunque flexible, formado en respuesta a una coyuntura histórica concreta, orientado a controlar o gobernar los gestos, pensamientos y comportamientos de los individuos, y compuesto por

\footnotetext{
${ }^{9}$ Cabe indicar que, para el caso de la comuna de Santiago, existe la Ordenanza N 62 , publicada en 1995 y modificada en 2006, que regula la "Realización de propaganda comercial que sea vista desde la vía pública”, y que en su Artículo $6^{\circ}$ plantea variadas prohibiciones entre las que se cuenta el pegar afiches o pintar letreros en/o sobre los muros de los edificios públicos, en los cierros de las propiedades, en las calzadas, aceras, soleras, puentes, monumentos, postes instalados en la vía pública, árboles de ornato público y, en general, en cualquier bien nacional de uso público..." (https://www.bcn.cl/leychile/navega r?idNorma=31089\&idVersion=2006-09 05\&idParte=8952404).
} 
elementos discursivos y no discursivos. No se trata de cualquier soporte, sino de vehículos estratégicos inscritos en relaciones de saber y de poder (...) cuyo objetivo es enfrentar una urgencia para obtener un efecto más o menos inmediato. (Bernasconi, en prensa, p. 20)

La noción de dispositivo de borramiento resulta relevante porque resalta la articulación de las prácticas con el poder, con el control del espacio y la intervención sobre los cuerpos señalada por Foucault (1994) en su clásico análisis. No se trata solo de una organización entre elementos, sino que una organización orientada por ciertos fines y propósitos urgentes: transformar las disposiciones de los sujetos y poblaciones afectados por los escritos, aplacar colectivizaciones, instalar una atmósfera gráfica hegemónica y monocorde, y un particular reparto de lo sensible en la ciudad, tal como lo define Rancière (2009).

En consecuencia, recurrir a la noción de dispositivo resulta plausible en la medida que entrega mayor inteligibilidad a un conjunto de prácticas que, de lo contrario, podrían parecer desperdigadas, cuando, en realidad poseen coherencia y consistencia debido a que buscan imponer una versión sobre lo que son la ciudad, el espacio público y los modos de actuación colectiva sobre ellos. Vale decir, prácticas que obtienen su sentido y su potencia de formar parte de un régimen de veridicción, esto es, siguiendo a Foucault, regímenes que indican qué es lo que tiene que ser conocido y cómo hacerlo (Burchell et al., 1991, como se citó en Bernasconi, en prensa).

El dispositivo de borramiento actúa sobre el territorio y sobre las personas, sobre el modo de vincularnos sensorial y corporalmente con el espacio urbano, desencadenando nuevas formas de territorialización, lo que nos recuerda lo dicho por Remedi (2006) en cuanto a que cabe considerar al espacio urbano como "un aparato ortopédico", una máquina que educa los cuerpos "y nos moldea a la fuerza", dando forma a "nuestros pensamientos, emociones y conductas" (p. 105). Quienes intervienen la ciudad borrando parecen saber de ello.

Corresponde, en consecuencia, un trabajo detenido y pormenorizado para dar cuenta de las territorialidades que activa el estallido social, así como aquellas que componen las prácticas de borramiento: las cualidades específicas de las inscripciones y su potencia sensorial, pero también su modo de articularse y componer citaciones, entramados y sistemas, la manera en que se sostienen y son sostenidas componiendo un régimen, los modos en que performan la sociedad en que vivimos y otras sociedades posibles. Este es el programa de investigación que pretendemos desarrollar $\mathrm{y}$ al que invitamos a las y los lectores de este texto. 


\section{REFERENCIAS}

Aguirre, N. (2020). Ideologías contemporáneas en la urbe: Análisis de las intervenciones a los Monumentos Históricos del Centro de Santiago. Revista Planeo, 42, 1-12.

Araya, P. (2007). Marcas expuestas, poéticas contestatarias. Escrituras en el espacio urbano chileno. En T. Orecchia-Havas (dir.). Les villes et la fin $d u$ XXème. siècle en Amérique Latine: Littératures, cultures, représentations (pp. 435-454). Bern: Peter Lang.

Artières, P. (2013). La police de lécriture. L'invention de la délinquance graphique 1852-1945. Paris: La Découverte.

Aubán, M. (2017). La dignidad de los márgenes. Aproximaciones afectivas a la ciudad informal. Revista INVI 32(91), 67-89.

Austin, J. (2003). Cómo hacer cosas con palabras (2a edic.). Buenos Aires: Paidós.

Bauerle, C. (2019). Los muros de la revuelta: La emergencia social grabada en las paredes. Cuadernos de Teoría Social 5(10), 138-150. Disponible en http:// www.cuadernosdeteoriasocial.udp.cl/index.php/tsocial/article/view/91

Bernasconi, O. (en prensa). Performación de sujetos de la violencia política mediante la genealogía de dispositivos. En O. Bernasconi, C. Fardella y S. Rojas Navarro (eds.). Exploraciones epistémicas para el estudio de los sujetos $y$ las subjetividades contemporáneas. Santiago de Chile: Editorial Universidad Alberto Hurtado.

Bernasconi, O. \& Ruiz, M. (2018). A performative and genealogical approach to the liminal subject's social sustenance: the case of the disappeared detainees in Chile. Subjectivity, 11, 228-249. https://doi.org/10.1057/s41286018-0050-5

Campos, L. (2019). Graphic Inscriptions and the Production of Urban Public Space in Valparaiso, Chile. En J. Hernández-García, S. Cárdenas-O’Byrne, A. García-Jerez, \& B. Beza (eds.). Urban Space: Experiences and Reflections from the Global South. Cali: Sello Editorial Javeriano.

Campos, L. (2020). Evade! Reflexiones en torno a la potencia de un escrito. Universum 35(1), 18-44. Doi: https://dx.doi.org/10.4067/S0718-23762020000 100018

Castillo, E. (2006). Puño y Letra: movimiento social y comunicación gráfica en Chile. ( $1^{\text {a }}$ edic.). Santiago: Ocholibros.

Cisternas, P., Loncón, P., y Klenner, J. (comps.) (2020). De Manifiesto. Expresiones ciudadanas a un año del estallido social. Puerto Varas: OsoLiebre.

Cristi, N., y Manzi, J. (2016). Resistencia gráfica. Dictadura en Chile: APJ - Tallersol. Santiago: Lom.

Deleuze, G. et Guattari, F. (1980). Mille plateaux. Capitalisme et schizophrenie. Paris: Minuit.

Delgado, M. (2015). El espacio público como ideología. Madrid: Catarata. 
Denis, J. et Pontille, D. (2009). Lécologie informationnelle des lieux publics: Le cas de la signalétique du métro. En C. Licoppe (ed.). Lévolution des cultures numériques, de la mutation du lien social à l'organisation du travail (pp. 94101). Limoges: FYP éditions.

Denis, J. et Pontille, D. (2010). Petite sociologie de la signalétique. Les coulisses des panneaux du métro. Paris: Presses de l'école des mines.

Denis, J. et Pontille, D. (2013). Ficelles pour une ethnographie de l'écrit. En C. Datchary (ed.). Petit précis de méthodologie. Le sens du détail dans les sciences sociales (pp. 17-30). Lormont: Le Bord de L'Eau.

Dittus, R. (2019). Las paredes hablan en Chile: crisis social, grafiti y arte callejero. Revista Chilena de Semiótica, 12, 198-214.

Errázuriz, L. (2009). Dictadura militar en Chile: Antecedentes del golpe estético-cultural. Latin American Research Review 44(2), 136-157. doi:10.1353/ lar.0.0095

Foucault, M. (1994). Hermenéutica del sujeto. Madrid: La Piqueta.

Fraenkel, B. (2002). Les écrits de septembre: New York 2001. Paris: Textuel.

Fraenkel, B. (2007). Actes d'écriture: quand écrire c'est faire. Langage et Société, 3, 101 - 112. doi : 10.3917/ls.121.0101

Fraenkel, B. (2009). Las escrituras de la catástrofe. Práctica de escritura y de lectura en la ciudad de Nueva York en septiembre 2001. Actuel Marx / Intervenciones, 6, 157-172.

Fraenkel, B. (2017). Actos de escritura: cuando escribir es hacer. Thémata. Revista de Filosofía, 56, 319-329.

Fraenkel, B. (2018). La notion d'événement d'écriture. Communication \& langages, 197, 35-52. doi: https://doi.org/10.3917/comla1.197.0035

Giglia, A. (2017). Espacios públicos, sociabilidad y orden urbano. Cuestión Urbana, 2, 15-28.

Juica, C. (2020). Valdivia presente. Valdivia: Ediciones Camino a Tar.

Lefebvre, H. (1974). La production de l'espace. Paris: Editions Anthropos.

Manzi, M. (2020). La ciudad de Santiago resignificada como corporeidad comunicacional temporal en tiempos de estallido social. Arquitecturas del Sur 38(57), 162-181. https://doi.org/10.22320/07196466.2020.38.057.09

Molina, R. (2020). Hablan los muros. Santiago: Lom.

Mondada, L. (2000). Décrire la ville: la construction des savoirs urbains dans l'interaction et dans le texte. Paris: Anthropos.

Morrison, C. (2020). Public Art Replacement on the Mapocho River: Erasure, Renewal, and a Conflict of Cultural Value in Santiago de Chile. Space and Culture 23(2), 149-163. https://doi.org/10.1177/1206331218770782

Latour, B. et Hermant, E. (1998). Paris ville invisible. Paris: Les Empêcheurs de Penser en Rond/La Découverte.

Latour, B. \& Weibel, P. (dir.) (2005). Making things public: Atmospheres of democracy. Cambridge: MIT Press.

Oliva, C. (2020). Monumentos en el estallido social como expresión material del derecho a la ciudad. Revista Planeo, 42, 1-6. 
Quiroga, D. y Pastén, J. (2020). Alienígenas. El estallido social en los muros. Santiago: Ocholibros.

Rancière, J. (2009). El reparto de lo sensible: Estética y política. Santiago: Lom.

Remedi, G. (2006). Ciudad letrada: Ángel Rama y la espacialización del análisis cultural. En M. Moraña (ed.). Ángel Rama y los estudios latinoamericanos (pp. 97-122). Chicago: Ediciones Universidad de Illinois.

Riffaud, T. et Recours, R. (2016). Le street art comme micro-politique de l'espace public: entre "artivisme» et coopératisme. Cahiers de Narratologie, 30, 1-10. Doi: 10.4000/narratologie.7484

Sandoval, A. (2001). Palabras escritas en un muro. El caso de la brigada Chacón. Santiago: Ediciones Sur.

Schindel, E. (2009). Inscribir el pasado en el presente: memoria y espacio urbano. Política y Cultura, 31, 65-87.

Searle, J. (2001). Actos de habla. Ensayo de filosofía del lenguaje. Madrid: Cátedra.

Slachevsky, P. (2020). Fragmentos de un Despertar. Santiago: Lom.

Suazo, V. (2019). Vuelta a la normalidad: borrar la memoria emancipatoria. Invitro. Blog del Instituto de la Vivienda de la Universidad de Chile. Disponible en https://invi.uchilefau.cl/vuelta-a-la-normalidad-borrar-la-memoriaemancipatoria/

Taylor, D. (2003). The archive and the repertoire: Performing cultural memory in the Americas. London: Duke University Press.

Vico, M. y Osses, M. (2009). Un grito en la pared. Santiago: Ocholibros. 